\title{
Development of the cultural and educational complex "Theatron", integrated into the historical environment of the youth theater building in Kazan
}

\author{
Valery Panov*, Margarita Gladysheva, and Andrey Razumov \\ National research Mordovian state University named after N. P. Ogarev, Saransk, Russia
}

\begin{abstract}
The article reveals the design features of a new type of multifunctional object Theatron in the context of the existing historical urban environment. The formation of a typologically new object is due to the increased attention of people to cultural and entertainment institutions offering a wide range of services. The need for proper integration of modern architecture into the existing historical development of the city is one of the most important tasks facing the architect. The authors proposed architectural and planning solutions and the creation of recreational space. Since many theater and entertainment structures are located in memorial sites of national significance, or are themselves valuable historical heritage, the reconstruction of theater buildings is a constant and inevitable phenomenon in all countries and is associated with complex controversial issues of simultaneous preservation and the existing buildings' improvement. In this regard, there is a constant need to "fit" such old buildings to the lifestyle of the modern audience and modern production methods of theaters in the XXXXI centuries. Due to the technology development, the technology of demonstration space, stage equipment and engineering equipment of the entire building have changed. In addition, serious urban development problems have also emerged over the years. The city scale has changed, the population has increased, and there is a rapidly growing tourist flow. Transport has changed, Parking lots for cars, communication with the metro, landing stages for unloading decorations and other cargo were needed. There are also aesthetic urban planning problems that do not allow freely, unreasonably expand the building, add the new volumes. This work can contribute to the further development and improvement of the proposed methodology for designing public cultural objects.
\end{abstract}

\section{Introduction}

Theater has always held a special place in the history of mankind, serving as a reflection of the cultural level, traditions and customs of a particular period of time. Throughout its history, the theater acted as the department of social thought, which formed moral ideals. Despite the

\footnotetext{
* Corresponding author: nikel_its_me@mail.ru
} 
active development of modern forms of art, including from cinematography, today theater, as before, occupies a separate niche with its own functions.

The need for the theater existence is due to its high social significance, since it is an actively visited platform for the consideration of acute socio-political issues, as well as a kind of educational institution that influences the expansion of the intellectual side of consciousness. And thereby contributing to the aesthetic taste, mental activity and political maturity development.

\section{Historical aspects of theatre formation}

The Youth Theater building is considered one of the most beautiful in Kazan, but it did not become one right away. Kazan citizens can still remember the protracted reconstruction of the theatre, caused by a big fire that happened ten years ago. But there is a silver lining without the good: it is the last one reconstruction has breathed a second life into this architectural and historical monument.

A house was built on the corner of present-day Ostrovsky and Najmi Streets at the end of the century before last by the merchant Zhuravlev, and in 1903 it was bought by the city authorities and wealthy citizens of Kazan for a merchant's collection. After the October Revolution, the Eastern Club, or, as it was officially called, the House of Tatar Culture, was opened here.

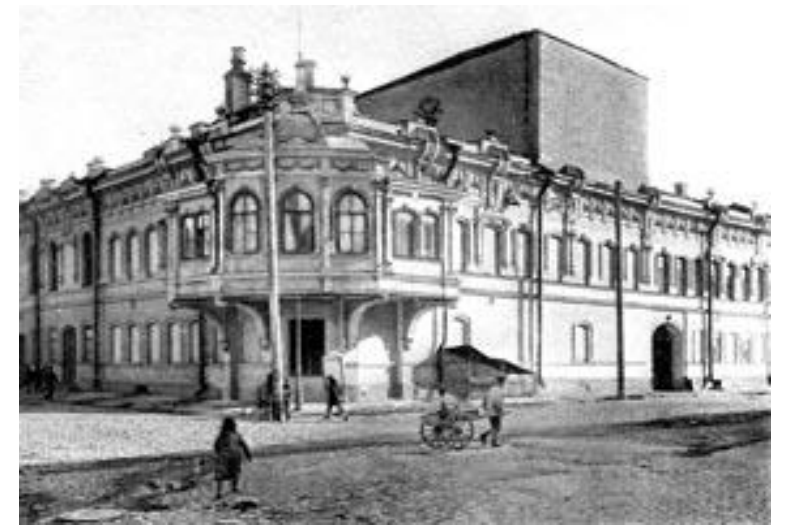

Fig.1. The residence of merchant meeting, 1903.

Around ten years before the First World War, there was quite a lively theatre life, and educational events were also held here. "In the merchant meeting, L. Tolstoy's lecture "Tolstoy as a teacher" was held in favor of the family and pedagogical circle "What should be taught and how should one teach?" - there were many such notes in the chronicles departments of the newspapers of that time.

The majority of theatre buildings are part of valuable historical buildings in cities, and often architectural or cultural monuments connected with historical events and famous cultural, artistic and political figures. Reconstruction of theatre and entertainment facilities is an inevitable phenomenon that is repeated from time to time.

The building, which passed from the Zhuravlyovs to the Potapovs, was not distinguished by its fortress and well-groomed appearance. Reporting on the fall of a piece of plaster from one building on Black Lake, the reporter was anxiously adding "A similar case could happen in a merchant meeting building, where the wall has caused a huge crack and threatens to drop plaster. The police have taken measures to protect the security fence". With the outbreak of World War I, one of the many city hospitals was housed in this building. Once again, a 
reporter from faraway 1915 said: "The first X-ray machine was purchased for Kazan hospitals at a cost of 5000 rubles. It was installed in a special room of City Hospital N 13 in the house of former Potapov on Voznesenskaya Street". At the same time, the Women's Medical Institute started to be organized in the same house of Potapov, which had already become city property. But there was a revolution here. Famous exhibitions were held here and performances by the Tatar company were staged, for which in 1924 the building inside was thoroughly rebuilt. The stage was significantly expanded and artistic latrines were fitted out. At the same time, the original appearance of the building was again greatly changed - several windows, vases on the parapet and moldings were lost. After the revolution, for some time there was the House of Tatar Culture in this building with a strong and active theatre division, and in 1940 the Youth Theater was opened.

In 1996, the Kazan State Youth Theater suffered a great deal of misfortune. The building on Ostrovsky Street, where the theatre had been located since its foundation in 1932, was severely damaged by fire. The restoration work lasted six years. But there is no loss without good - the renovated building of the theatre has become a real masterpiece both outside and inside. The original evening lighting attracts the attention of passers-by and serves as additional advertising. And the interiors of the Youth Theatre make it a real fairytale palace. A visit to the theatre will remain in the memory of both small and adult spectators for a long time. The foyer, staircases and auditoriums are decorated with marble and decorated with gold. Prevailing in finishes white creates a sense of solemnity and spaciousness. And the red velvet of the curtain concentrates all the attention on stage.

Today it is a two-storey building with an elegant exterior decoration in an eclectic style and a large bay window - a convex "capsule" above the roof that gives the necessary volume to the stage. The Youth Theater (at that time named after Lenin Komsomol) was located here in 1940, becoming one of the most popular cultural centres of Kazan, especially during the Great Patriotic War.

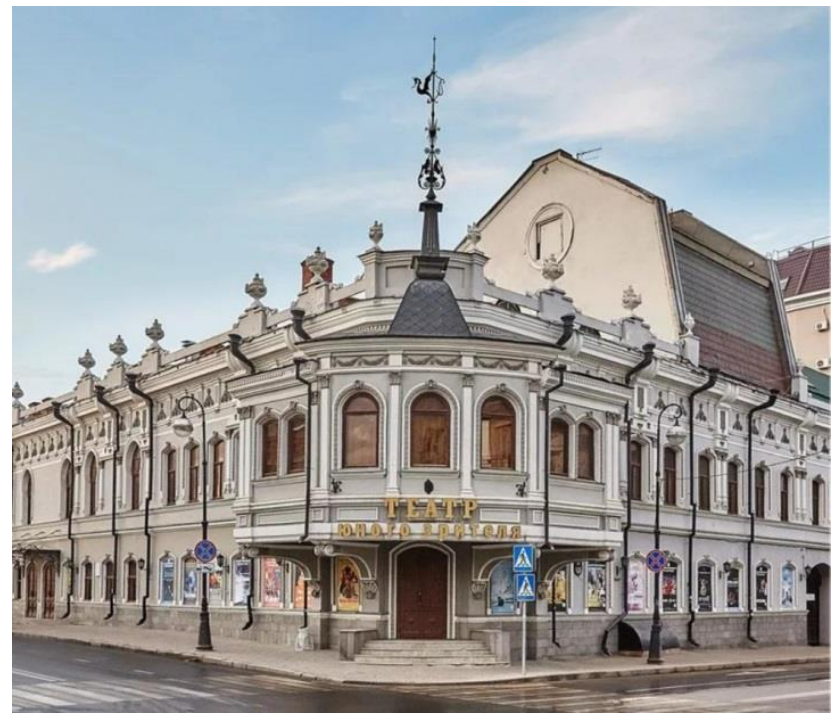

Fig. 2. The buildings of the Kazan Cultural Centre in 2020.

\section{Conceptual and theoretical model of Youth Theater formation}

The project task was to transform the premises depending on the conditions, making maximum use of the entire area, which would be in line with the current flow of architecture. 
Yesterday we could see the building of former warehouses, which were built in the middle of the 19th century to a design by architect Pyatnitsky P. G. Today we see a functioning Youth Theater and an abandoned territory of the old warehouses, a semi-destroyed building.

And in future we would like to create a cultural and educational complex «Theatron» with 3 new stages, an ennobled multifunctional territory, a hostel and a school, and the Youth Theater.

«Time is the most powerful thing in this world» is an ancient Indian wisdom. In our project, we turned to the heritage of Ancient Greece and Ancient Rome, an association which comes with the same idea of columns and theatre. Both of these terms are directly related to the Theatre, which is why it was decided to use the vast outdoor area in the courtyard as a multifunctional stage and attraction center for all visitors.

The project proposal shows that each of the stages has its own development. For example, using a gymnasium-shaped area to have a stage in the center and seating areas all around the perimeter. It was planned to close this area in different places to move and expand the stage with separate seating sectors. Each idea was also considered. In the end, we settled on the one that emphasizes the geometry of the space and at the same time adapts to any event. The Youth Theatre - a place for spectators, an amphitheater bordered by an orchid on a slope of a gentle hill.

\section{Planned space structure}

The space has been created from existing guides, which are shaped like a yard. This principle allows the design solution to use most of the existing yard without leaving "empty" spaces. Firstly, the principle of using guides is optimal for designing reconstructions of public areas, because there is no need to look for new forms and ideas from outside, you can to turn to what we have. This allows the person (visitor) to feel comfortable in a new environment, without feeling a resonance between old and new forms. When we were looking for forms and solutions for our stages and amphitheaters, we thought about one of Professor Michelangelo Pivvete's questions "what for", which means "for what or why". So that is what we need to come up with new shapes for, if there is already something that "works" one way or another. Tracks or paths run along buildings and are an extension of them, without distorting the space and allowing visitors to feel free to move around.

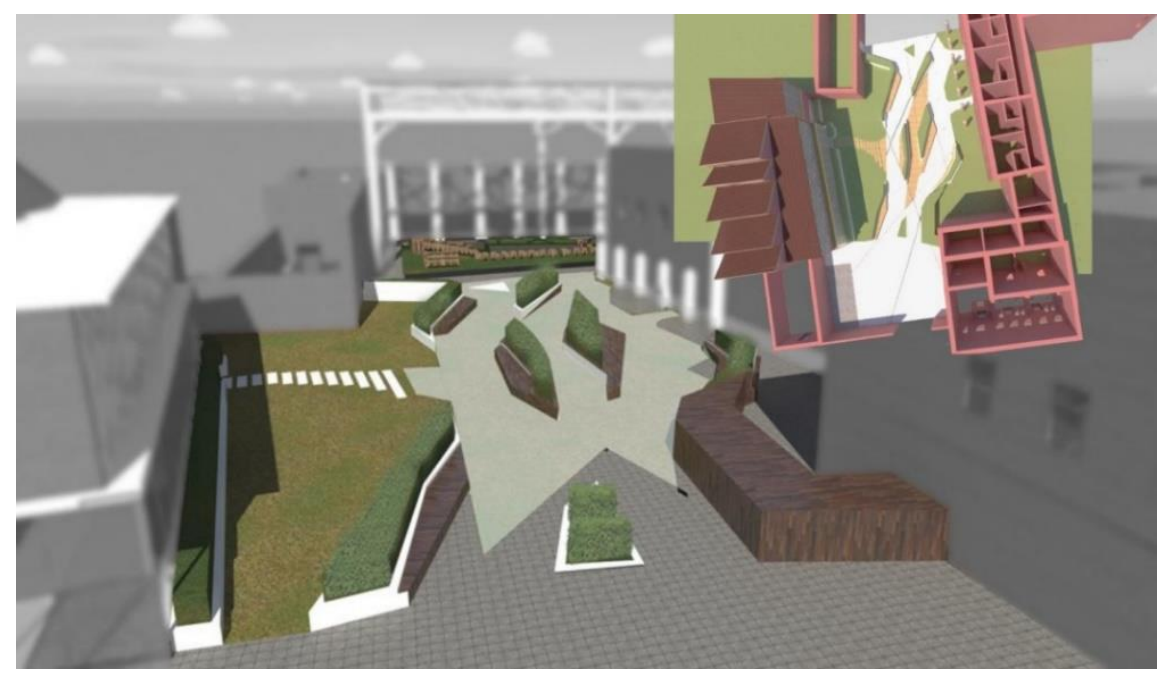

Fig. 3. Project proposal for the "Theatron" recreation space 
The amphitheater shape, the roof segments, the landscape, the park zone - all of this is perceived by the eye as one organism in our concept.

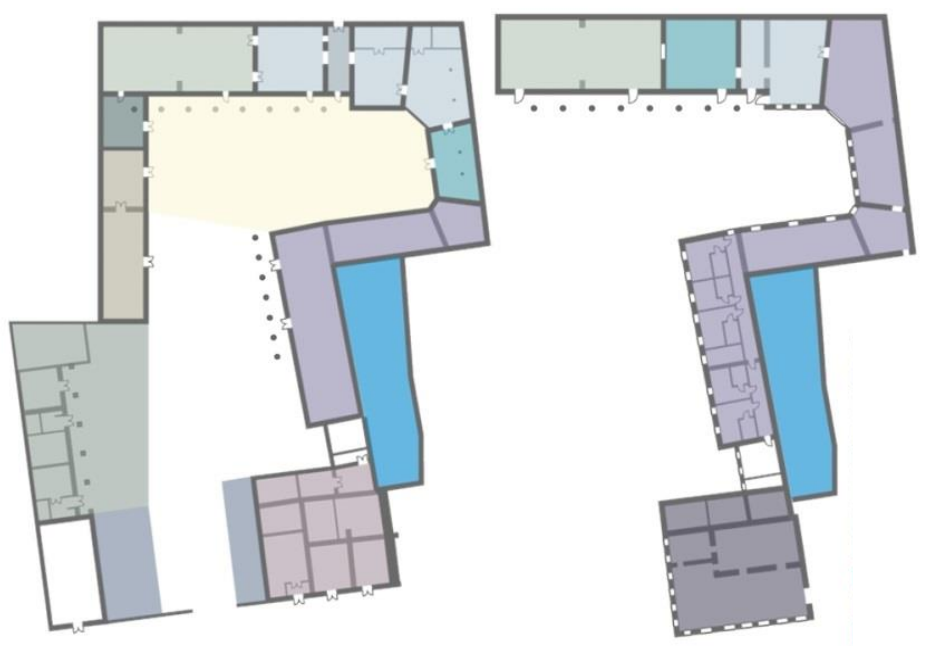

Fig. 4. Theatron functional zoning scheme

\section{Project proposals}

The project proposes a new entrance from the side of Pravo-Bulochnaya Street, where the flow of people into the courtyard will be divided into two parts: one - a large one - the Youth Theatre with a stage created by the landscape and changes in altitude marks; the second stage with a small amphitheater and a transformable stage.

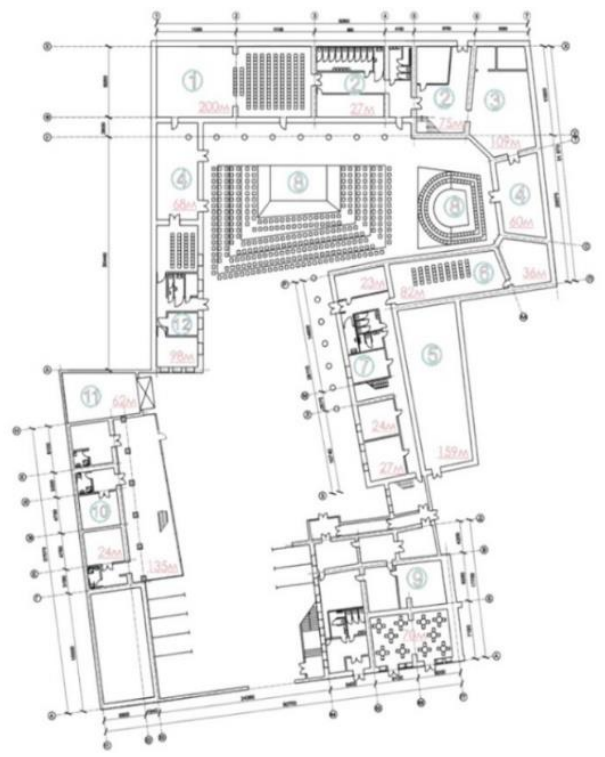

\section{1st floor plan}

1- Black box

2- Lobby

3- Free use premises

4- Utility room

5- Warehouse

6- Lecture hall

7- Training Classes

8- Amphitheater

9- Food court

10- Hostel

11- Garage

12- Inclusive Theater / Bay Bi

Theater

Fig. 5. Project proposal for the plan of the 1-st floor of the "Theatron" 
There can be up to two rows of seats in each sector. A simple and convenient design for chairs has been developed. These are two types of seats that can be folded together like "Lego" to form a third type of seat. When there are no performances, these chairs can be partially enclosed in the openings under the stage, partially assembled into "bricks" and folded into a new space for spending time. After all, apart from the performances, people can come there to sit, chat, drink coffee, read and dance.
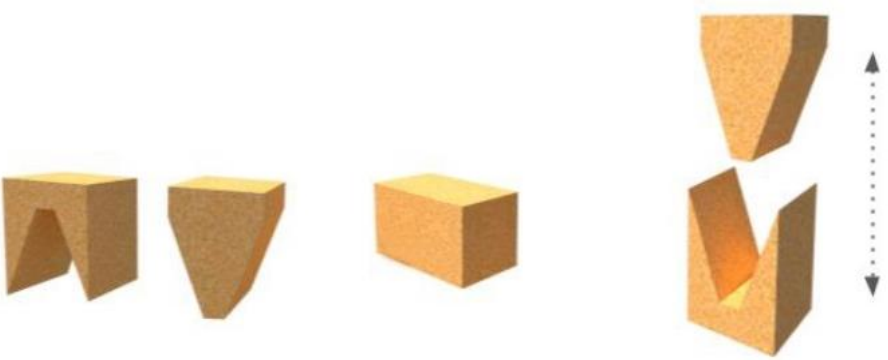

Fig. 6. Project proposal for chair design.

The second part of the square also consists of an amphitheater with 80 seats and a stage in front of it. There are two factors that make this area special - interactivity and compactness. On the wall in front of the amphitheater, we decided to take a stable screen that will cover the unfavorable facade and the view of the building behind it. The screen itself can be used in summertime for performances in a new form - performances without gravity, when artists walk on a vertical stage, or for film screenings, as well as for interactive theatre, where the viewer decides how the action will continue.

The roof will transform according to the season and weather conditions. Training rooms and workshops were created, we left the Black box, an inclusive and baby theatre was placed on the site of the archive building, and technical rooms were made for each stage.

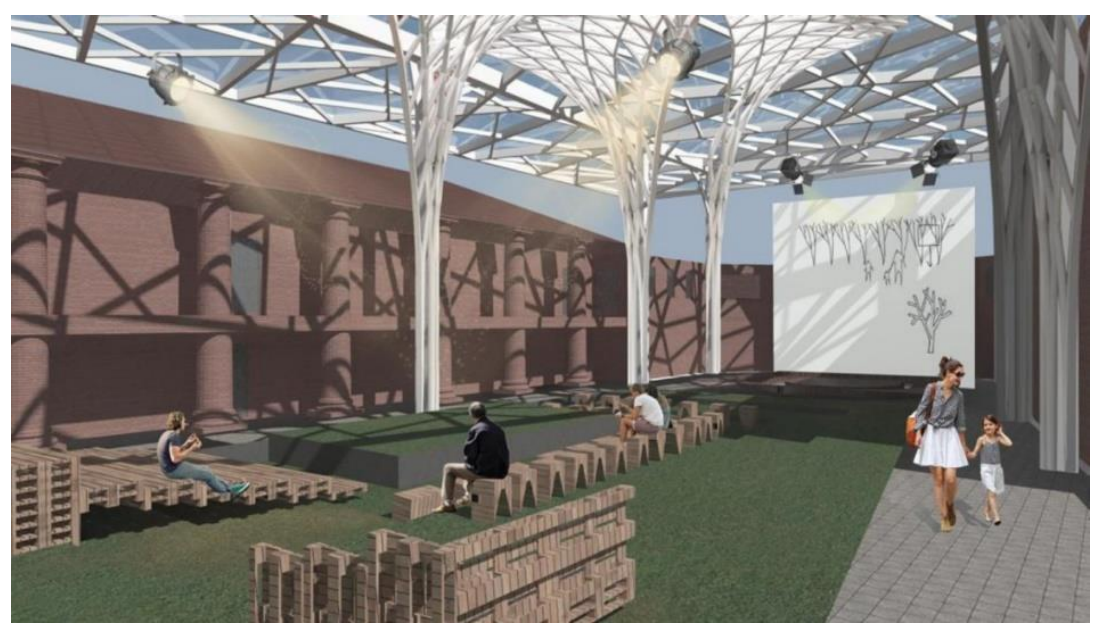

Fig. 7. Project proposal for the amphitheater and the concept for the "Theatron" roof solution the 
Black box scene

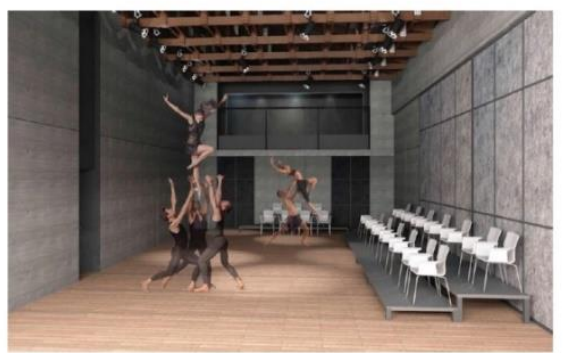

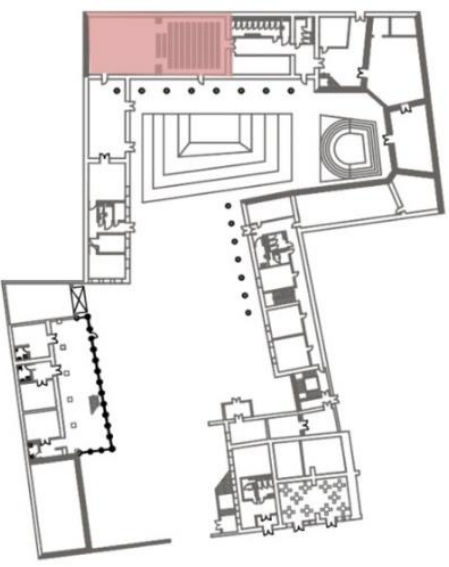

Fig. 8. Project proposal for the "Theatron" stage

The hostel was also designed as a project. Above the existing building, a first floor was added, the ground floor was placed behind a glass wall to preserve the view of a part of the historic building with columns. In this way received the "house in the house". The windows are south-facing, with two rooms for small groups on the ground floor.

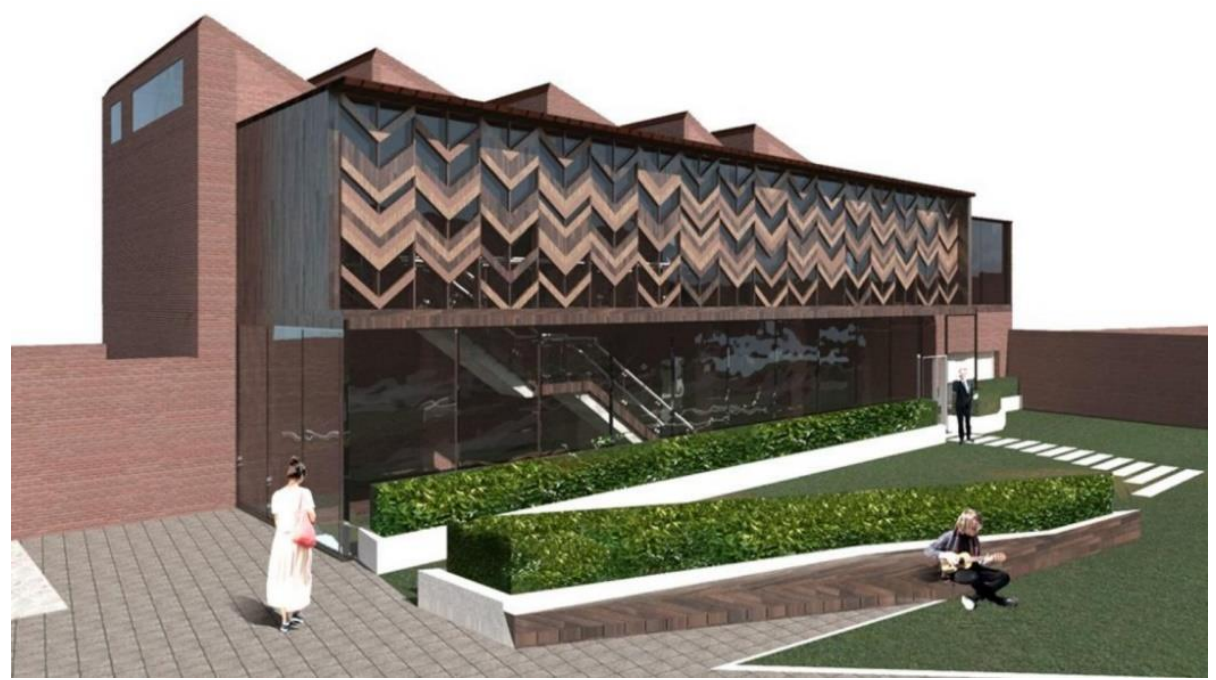

Fig. 9. Prospective view of the "Theatron" building project proposal

\section{Main advantages of the "Theatron"}

Maximum use of open large area in the center: transformers seats for performances, the education sector, hostel with parking, food court in an existing theatre building, separate technical room for black box.

All this will increase the number of visitors and expand the circle of people (youth, instant, families, schoolchildren). The Youth Theatre will be another attraction for New Year fairs, various shows, cultural events and concerts, as well as celebrations.

Main advantages of the Theatre: 
- new entrance from the Pravo-Bulochnaya Street, with the possibility of making a cash register for open-air performances or fairs

- additional protection of historical buildings from rainfall and destructive environmental factors. Better preservation of the monument.

- The maximum efficiency of using expensive land in the historical part of the city.

- attraction of new population groups by expanding the functionality of the theatre. In fact, the transformation of the Youth Theatre into a multifunctional interactive educational and entertainment center.

\section{How will "Theatron" affect the environment, what will happen to it in the future?}

In conclusion, when working in the context of a historic city, it is impossible to form a certain universal path to a positive outcome. Finding a harmonious combination of a newly designed facility with a historically established structure is a difficult task. The real architectural practice involves close interaction with the environment. A modern architect needs to be sensitive to existing development by constructing new buildings in such a way that the old and new harmoniously coexist in the architectural and spatial environment of the city. We have developed a functioning scenario. The scenario is a simulation of people's lives in dynamics. We need to understand what processes take place in time or will take place elsewhere.

\section{Conclusion}

The architect does not only build houses, but also invents and programmes the environment in which specific people will live and specific events will take place. Of course, erecting the physical body of the building remains the architect's task, but it is equally important to develop interesting scenarios for living in and around the building - who will do this and how. How will the building be used; how will it affect the environment and what will happen to it in the future? The architect is responsible, including social responsibility for the continued existence of the house he or she has built.

The proposed project to develop the cultural and educational complex "Theatron", integrated into the historical environment of the building of the Youth Theatre in the city of Kazan, will help a modern architect to competently integrate the new volume into the existing architectural and spatial environment of the city, not replacing, but accompanying a creative act.

\section{References}

1. A.V. Anisimov, Theater buildings in Moscow. History and architecture (KURS, M., 2017)

2. V.E. Bykov, E.I. Okuneva, V.V. Shchepetov. Theaters of the young spectator and puppet theaters. Recommendations for design (Stroyizdat, Moscow, 1972)

3. V.M. Vinogradova, V.D. Krasilnikova, L.D. Chumakova, Modern theater building (ed. by V. M. Vinogradov, V. D. Krasilnikov, L. D. Chumakov, Stroyizdat, Moscow, 1986) $195 \mathrm{p}$.

4. Yu.A. Devyatova, Architecton: Izvestiya vuzov 53, (2006). http://archvuz.ru/2016_1Z5

5. K.N. Kalugina-Pablos, Academia. Architecture and construction 4, 160 (2016) 
6. D.F. Lazarev, E.P. Eremina, Staged warehouses: album-catalog (Giproteater, M., 1986)

7. D.F. Lazarev, T. Rozno, Year. Workshops of theaters: album catalog (Giprotheater, M., 1987)

8. A.A. Magay, S.A. Zabelina, E.A. Bulgakova, Construction technique bulletin 6 (994), 58-59 (2017)

9. The normal. Theatres. Production premises and reserve warehouses: typical design5.1.2.2.-72. - M.: Central Institute of Standard Design, 1972. - 501.

10. Normals. Theatres. Scenes of types 1, 2, 3, 4 and rooms for stage maintenance: typical design-5.1.2.1-71. - M.: Central Institute of Standard Design, 1971. - 421.

11. On approval Of the concept Of long-Term development of theater business in the Russian Federation until 2020: decree of the Government of the Russian Federation. Of the Russian Federation dated June 10, 2011 No. 1019-p. - URL: http://docs.cntd.ru/document/902284436

12. E.I. Okuneva, Theaters of the young spectator (Stroyizdat, Moscow, 1976)

13. M.P. Stul', Theatrical culture and creative thinking of schoolchildren, The Soviet pedagogy 4, 24-28 (1989)

14. A.S. Tikhomirov, Norms of technological design of theaters (Giprotheater, M., 1978)

15. V.M. Shkolnikov, Safety rules for theaters and concert halls (Ministry of culture of the USSR, M, 1981)

16. B.V. Shchepetov, Theaters. Recommendations for the design of theatres with the grate deep scenes. Auditorium and stage (Vol. 1., Central research Institute, M., 1970)

17. B.V. Shchepetov, Theaters. Recommendations for the design of theatres with the grate deep scenes. The theatre premises (Vol. 2., Central research Institute, M., 1971)

18. Philosophical encyclopedia (INFARA-M, Moscow, 1998)

19. I.A. Kheruvimova, B.A. Curlyaev, History and modern architecture of the theatre (PSUAC, Penza, 2014)

20. K.L. Lidin, M.G. Meerovich, E.A. Bulgakova, S.A. Zabelina, Journal of Advanced Research in Law and Economics 8(2), 496-504 (2017)

21. Hardy Holzman Pfeiffer Associates. Theaters 0th Edition (Back Stage Books, 2000) 